\title{
BMJ Open Predictors of oral anticoagulant- associated adverse events in seniors transitioning from hospital to home: a retrospective cohort study protocol
}

\author{
Harsukh Benipal, ${ }^{1}$ Anne Holbrook (D) , , ${ }^{1,2}$ J. Michael Paterson,, ${ }^{3,4}$ James Douketis, ${ }^{5,6}$ \\ Gary Foster, ${ }^{1,7}$ Lehana Thabane ${ }^{1,7}$
}

To cite: Benipal H, Holbrook A, Paterson JM, et al. Predictors of oral anticoagulant-associated adverse events in seniors transitioning from hospital to home: a retrospective cohort study protocol. BMJ Open 2020;10:e036537. doi:10.1136/ bmjopen-2019-036537

- Prepublication history for this paper is available online. To view these files, please visit the journal online (http://dx.doi. org/10.1136/bmjopen-2019036537).

Received 18 December 2019 Revised 01 May 2020 Accepted 28 May 2020

\section{ABSTRACT}

Introduction Oral anticoagulants (OACs) are widely prescribed in older adults. High OAC-related adverse event rates in the early period following hospital discharge argue for an analysis to identify predictors. Our objective is to identify and validate clinical and continuity of care variables among seniors discharged from hospital on an OAC, which are independently associated with OAC-related adverse events within 30 days.

Methods and analysis We propose a population-based retrospective cohort study of all adults aged 66 years or older who were discharged from hospital on an OAC from September 2010 to March 2015 in Ontario, Canada. The primary outcome is a composite of the first hospitalisation or emergency department visit for a haemorrhage or thromboembolic event or mortality within 30 days of hospital discharge. A Cox proportional hazards model will be used to determine the association between the composite outcome and a set of prespecified covariates. A split sample method will be adopted to validate the variables associated with $0 \mathrm{AC}$-related adverse events. Ethics and dissemination The use of data in this project was authorised under section 45 of Ontario's Personal Health Information Protection Act, which does not require review by a research ethics board. Results will be disseminated via peer-reviewed publications and presentations at conferences and will determine intervention targets to improve OAC management in upcoming randomised trials.

Trial registration number ClinicalTrials.gov Identifier: NCT02777047; Pre-results.

\section{INTRODUCTION}

\section{Background/rationale}

(C) Author(s) (or their employer(s)) 2020. Re-use permitted under CC BY-NC. No commercial re-use. See rights and permissions. Published by BMJ.

For numbered affiliations see end of article.

Correspondence to

Dr Anne Holbrook;

holbrook@mcmaster.ca
Oral anticoagulants (OACs) are commonly prescribed for the prevention and treatment of stroke, systemic embolism and venous events associated with atrial fibrillation (AF) and venous thromboembolism. ${ }^{1-3}$ Despite the introduction of direct-acting oral anticoagulants (DOACs), which do not require routine laboratory monitoring and are associated with less bleeding than warfarin, OACs remain a top cause of serious drug-related
Strengths and limitations of this study

- Few studies have examined factors that predict medication safety adverse events during periods of transitions of care.

- In this large, population-based cohort study of seniors, we examine both clinical and continuity of care risk factors for oral anticoagulant-related adverse events post-hospitalisation.

- This study is subject to the limitations inherent in observational design and the use of health administrative databases.

harm, primarily bleeding and thromboembolic events. ${ }^{45}$

It is estimated that between 2013 and 2014, OACs were implicated in 28\% (95\% CI 23\% to $32 \%$ ) and $39 \%$ (95\% CI $33.7 \%$ to $43.8 \%$ ) of emergency department (ED) visits in the USA for adverse drug events among adults aged 65-79 years and those 80 years or older, respectively. ${ }^{6}$ In Canada, it is estimated that OACs account for $12.6 \%$ of adverse drug reaction-related hospitalisations among seniors between 2006 and 2011.

Observational studies using populationlevel data report even higher adverse event rates for OAC users during periods of transitions in care, specifically during the early post-hospitalisation period. Among the elderly, a bleeding risk of $26.4 \%$ (95\% CI 25.3-27.4) per person-year and a thromboembolic event risk of $32.4 \%$ (95\% CI 31.3 to 33.5) per person-year were identified in $\mathrm{OAC}$ users within the first 30 days after hospital discharge. ${ }^{8}$

The high rates of adverse events in the early post-discharge period suggest that continuity of care during this hectic time for patients transitioning out of the hospital may be part of the problem. ${ }^{910}$ Continuity of care is defined by the WHO as 'the degree to which discrete 
health care events are experienced by people as coherent and interconnected over time and consistent with their health needs and preferences'. ${ }^{11}$ Several studies have found that prompt primary care follow-up of patients after hospital discharge reduces subsequent ED visits and hospitalisations among patients with chronic conditions such as congestive heart failure, chronic obstructive pulmonary disease, myocardial infarction and cancer. ${ }^{12-18}$ Many clinical practice guidelines recommend physician follow-up within 1-2 weeks postdischarge as best practice to improve continuity of care..$^{10-24}$

Coordinating medication management posthospitalisation is challenging, with adverse drug events reported as among the most common reason for postdischarge re-admission and ED visits. ${ }^{25-27}$ Poor medication management immediately following hospital discharge has been reported to increase the risk of 30-day readmission by $28 \% .^{28}$ Therefore, understanding which factors, including patient, hospital, provider and medicationrelated factors, predict adverse clinical outcomes, will be important to reducing adverse outcomes, re-admissions and costs.

This study aims to identify important risk factors, both clinical and continuity of care, which predict OAC-related harm in the short-term period following hospitalisation. Validated process of care risk factors may be useful targets for future intervention trials.

\section{Objectives}

Research question: Among Ontario residents aged 66 years or older who were discharged from hospital on an OAC (warfarin, dabigatran, rivaroxaban or apixaban), which clinical and continuity of care variables are significantly associated with time to re-hospitalisation or an ED visit for a haemorrhage or thromboembolic event, or mortality within 30-days post-discharge?

Hypothesis: In addition to traditional clinical risk factors for OAC-related adverse events, factors related to continuity of care, particularly contact with a primary care physician, nurse practitioner, medical specialist or home care services within 7 days of discharge, will be associated with lower risk for the composite outcome in the 30 days following hospitalisation.

\section{METHODS AND ANALYSIS}

Reporting will be compliant with Strengthening the Reporting of Observational Studies in Epidemiology recommendations.

\section{Study design}

We will use a population-based retrospective cohort study to identify potential patient, provider and institution-level factors and continuity of care factors independently associated with OAC-related adverse events in seniors using routinely collected administrative health data. These data are more accurate than self-reported data and minimise selection bias as the database includes the entire population of interest. ${ }^{29} 30$

\section{Setting}

Our study will be set in Ontario, Canada. Ontario is Canada's most populous province, with over 14 million residents in 2018, representing about $39 \%$ of the country's population. $^{31}$

\section{Data sources}

The study dataset will be created using the province of Ontario's health administrative databases housed at ICES. These databases contain administrative health service records for the approximately 14 million Ontarians eligible for health coverage. ${ }^{32-36}$ These databases are linked using encrypted patient-specific identifiers. Table 1 summarises the database names and contents of those that will be used to create the study dataset.

\section{Observation period}

We define the study's index date as the date of OAC dispensing, which had to be within 1 day of hospital discharge. The patient accrual period will be 1 September 2010-31 March 2015. This period captures the time following the approval of DOACs by Health Canada and allows for a sufficient sample size to conduct this study. ${ }^{37}$

We will define a 7-day post-discharge blanking period during which patients will have been dispensed an index OAC, but study outcome events will not be measured. All patients who died or experienced a hospitalisation or an ED visit for a thromboembolic or haemorrhagic event within the 7-day blanking period will be excluded. For those who remain in the cohort, healthcare contacts during the blanking period will be recorded.

Patients will be followed from the end of the blanking period (day 8) until day 30 post-hospitalisation (or a maximum follow-up of 24 days), with the last outcome event date being 30 April 2015. We will assume that all patients continuously use OACs during follow-up. However, patients will be censored at a hospitalisation lasting more than 5 days, as information on in-hospital medications are not available in administrative claims data and medications are often changed or discontinued during hospital admission. ${ }^{38} 39$

\section{Participants}

\section{Inclusion and exclusion criteria}

The source population will be all Ontario residents aged 66 years or older who are discharged from an acute care hospital and dispensed a single OAC-warfarin, dabigatran, apixaban or rivaroxaban at any dose, within 1 day of discharge. Patients with a most responsible discharge diagnosis of major bleeding, defined as any bleeding event that was the cause for the hospitalisation or contributed to the greatest fraction of the length of stay, will be excluded. ${ }^{40}$ We will use the Ontario Health Insurance Plan Registered Persons Database, which contains insurance coverage, demographic, place of residence and vital status information, together with the Canadian Institute 
Table 1 Description of ICES databases

\begin{tabular}{ll} 
Name of database & Content of database \\
\hline $\begin{array}{l}\text { Canadian Institute for Health } \\
\text { Information-Discharge Abstract } \\
\text { Database (CIHI-DAD) }\end{array}$ & $\begin{array}{l}\text { Patient-level demographic, diagnostic, procedural and } \\
\text { treatment information on all acute care hospitalisations. }\end{array}$ \\
$\begin{array}{l}\text { Canadian Institute for Health } \\
\text { Information- }\end{array}$ & $\begin{array}{l}\text { Patient-level demographic, diagnostic, procedural and } \\
\text { treatment information for all hospital-based and community- } \\
\text { National Ambulatory Care }\end{array}$ \\
based ambulatory care.
\end{tabular}

Reporting System (CIHI-NACRS)

Client Agency Program Enrollment Database (CAPE)

Information regarding enrolment of individuals with primary care practitioners, teams and networks.

ICES-derived Cohorts

Validated cohorts of individuals with specific diseases and conditions. These include: the Ontario Congestive Heart Failure

Database $(\mathrm{CHF})^{54}$; Ontario Dementia Database (DEMENTIA $)^{55}$; Ontario Diabetes Database (ODD) ${ }^{56}$; and Ontario Hypertension Dataset (HYPER). ${ }^{57} 58$

ICES Physician Database (IPDB)

Characteristics of physicians and surgeons licenced to practice in Ontario.

Ontario Cancer Registry (OCR)

Ontario Continuing Care Reporting System (CCRS)

Ontario Drug Benefit Program Database (ODB)

Ontario Health Insurance Plan Claims History Database (OHIP)

Ontario Health Insurance Plan Registered Persons Database (RPDB)

\section{Ontario Home Care Database (HCD)}

Ontario Mental Health Reporting System Database (OMHRS)

\section{Ontario Ministry of Health and Long-Term Care Institution} Information System

Resident Assessment Instrument-Contact Assessment (RAICA)

Resident Assessment Instrument-Home Care (RAI-HC)

Statistics Canada Census Postal Code Conversion File
Patient-level demographic, cancer diagnosis and cancerrelated mortality information.

Demographic, clinical, functional and resource utilisation information on individuals receiving hospital-based complex continuing care services.

Records of dispensed outpatient prescriptions paid for by the provincial government.

Claims for physician services paid for by the provincial government.

Demographic, place of residence and vital status information for all persons eligible to receive insured heath services in the province.

Patient-level demographic, diagnostic, procedural and treatment information on all home care visits.

Patient-level demographic, diagnostic, procedural and treatment information on all adult inpatient mental health visits.

Ontario healthcare institution information.

Patient-level demographics, diagnosis and treatment information used to guide intake of patients into home care services.

Contains data that assess the care and needs of adult patients in hospital and community settings for in-home and placement services.

Information on rural residence and income quintiles of residents. for Health Information Discharge Abstract Database, to identify the study patients. We will also access the prescription drug claims history of eligible patients via the Ontario Drug Benefit Plan Database. These datasets are linked using unique coded identifiers and will be analysed at ICES (www.ices.on.ca).

The age threshold of 66 years will be applied to capture prescription use by study participants at least 1 year prior to study enrolment, as Ontario Drug Benefits programme eligibility begins at the age of 65 years. This will avoid incomplete or missing prescription drug data for study participants. $^{41}$

\section{Variables}

Outcomes

The primary outcome will be a composite of hospitalisation or ED visit for a haemorrhage or thromboembolic event, or death from any cause. These events are standard in pivotal trials and are the main OAC-associated serious 
Table 2 Diagnosis and procedure codes used to define thromboembolic outcomes

\begin{tabular}{|c|c|c|}
\hline Thromboembolic event type & ICD-10 codes & $\begin{array}{l}\text { Canadian Classification of Health } \\
\text { Interventions codes }\end{array}$ \\
\hline Deep vein thrombosis & $\begin{array}{l}\text { I82.8, I82.9, I80.1, I80.2, I80.3, } \\
\text { I80.8, I80.9, I82.0, I82.1, I82.2, } \\
\text { I82.3 }\end{array}$ & \\
\hline Pulmonary embolism & I26.0, I26.9 & \\
\hline Ischaemic stroke & $\begin{array}{l}163.0,163.1,163.2,163.3,163.4 \\
163.5,163.6,163.8,163.9,164 \\
\text { H34.1, H34.2, H34.8, H34.9 }\end{array}$ & \\
\hline Transient ischaemic attack & $\begin{array}{l}\mathrm{H} 34.0, \mathrm{G} 45.0, \mathrm{G} 45.1, \mathrm{G} 45.2 \\
\mathrm{G} 45.3, \mathrm{G} 45.8, \mathrm{G} 45.9\end{array}$ & \\
\hline $\begin{array}{l}\text { Peripheral vascular disease or emergency } \\
\text { rescue procedure }\end{array}$ & $\begin{array}{l}\text { I70.0, I70.1, I70.20, I70.21, I70.8, } \\
170.9,173.1,173.8,173.9, \mathrm{~K} 55.1\end{array}$ & $\begin{array}{l}\text { 1KA76, 1KA50, 1KE76, 1KG50, 1KG57, } \\
\text { 1KG76, 1KG87, 1IA87, 1IB87, 1IC87, } \\
\text { 1ID87, 1KA87, 1KE57 }\end{array}$ \\
\hline
\end{tabular}

ICD-10, International Classification of Diseases, 10th revision.

adverse events. Including death also avoids the problem of competing risks. ${ }^{42-46}$

Thromboembolic events will include venous thromboembolic events (deep vein thrombosis and pulmonary embolism) and arterial thromboembolic events (ischaemic stroke or transient ischaemic attack, peripheral vascular disease or emergency rescue procedure, or systemic embolism). The International Classification of Diseases (ICD) 10th revision diagnosis codes, and the Canadian Classification of Health Interventions procedure codes for these conditions are provided in table 2. Validation studies have found equivalent ICD-9 diagnosis codes to have $91 \%$ sensitivity and $95 \%$ specificity. ${ }^{47-51}$ Haemorrhagic events will include intracranial bleeds, upper and lower gastrointestinal bleeds and any other bleed that required a hospital admission or a visit to an ED. Table 3 lists the ICD-10 diagnosis codes used to define haemorrhage. Validation studies found equivalent ICD-9 diagnosis codes to have $94 \%$ sensitivity and $83 \%$ specificity for major haemorrhagic events. ${ }^{49}$
The outcomes will be ascertained using Canadian Institute for Health Information Discharge Abstract Database, Canadian Institute for Health Information National Ambulatory Care Reporting System, and Ontario Health Insurance Plan Registered Persons Database. ${ }^{52} 53$

\section{Risk factors}

Table 4 summarises the clinical and continuity of care risk factors being explored in this project, as well as their data sources. Patient demographic characteristics captured as of the date of cohort entry will include age, sex, socioeconomic status (as defined by census neighbourhood income quintiles), rural residence and whether the patient is rostered with a primary care physician. In addition, palliative patients will also be identified using a previously validated combination of codes in health administrative databases. ${ }^{54}$

Characteristics of the index hospitalisation including type of hospital, length of index hospitalisation and

Table 3 Diagnosis codes used to define haemorrhage outcomes

\begin{tabular}{ll}
\hline Haemorrhage type & ICD-10 codes \\
\hline Intracerebral & I60, I61, I62.0, I62.1, I62.9, S06.400, S06.401, S06.410, S06.411, S06.420, S06.421, S06.430, S06.431, \\
& S06.440, S06.441, S06.490, S06.491, S06.500, S06.501, S06.510, S06.511, S06.520, S06.521, S06.530, \\
& S06.531, S06.540, S06.541, S06.590, S06.591, S06.600, S06.601, S06.610, S06.611, S06.620, S06.621, \\
& S06.630, S06.631, S06.640, S06.641, S06.690, S06.691 \\
Upper & I85.0, I98.20, I98.3, K22.10, K22.12, K22.14, K22.16, K22.6, K25.0, K25.2, K25.4, K25.6, K26.0, K26.2, \\
gastrointestinal & K26.4, K26.6, K27.0, K27.2, K27.4, K27.6, K28.0, K28.2, K28.4, K28.6, K29.0, K63.80, K31.80, K92.0, \\
& K92.1, K92.2 \\
Lower & K55.20, K62.5 \\
gastrointestinal & N02.0, N02.1, N02.2, N02.3, N02.4, N02.5, N02.6, N02.7, N02.8, N02.9, K66.1, N93.8, N93.9, N95.0, \\
Other & R04.1, R04.2, R04.8, R04.9, R31.0, R31.1, R31.8, R58, D68.3, H35.6, H43.1, H45.0, M25.0 \\
\end{tabular}

ICD-10, International Classification of Diseases, 10th revision. 
Table 4 Clinical and continuity of care variables and data sources

\begin{tabular}{l}
\hline Variable \\
\hline Patient characteris \\
Age \\
Sex \\
Income quintile \\
Rural residence
\end{tabular}

Data source

Rostering: patient enrolled in a primary care organisation, team or with a primary care physician

Palliative patient: look-back window of 6 months

HIP, CIHI-DAD, CIHINACRS, RAI-CA, RAI$\mathrm{HC}, \mathrm{HCD}, \mathrm{CCRS}$

\section{Characteristics of index hospitalisation}

$\begin{array}{ll}\begin{array}{l}\text { Type of hospital: teaching, } \\ \text { community, small }\end{array} & \begin{array}{l}\text { Ontario Ministry of } \\ \text { Health and Long-Term } \\ \text { Care }\end{array} \\ \begin{array}{ll}\text { Length of index hospitalisation } & \text { CIHI-DAD } \\ \text { Specialty of the physician } & \text { IPDB } \\ \text { responsible for index OAC } \\ \text { prescription: general/family } \\ \text { practitioner; cardiology; } \\ \text { haematology; internal medicine; } \\ \text { orthopaedic surgery; oncology; other } \\ \text { surgery; other }\end{array}\end{array}$

Type of OAC dispensed at index ODB

prescription date: warfarin,

apixaban, dabigatran, rivaroxaban

Type of discharge: home; long-term CIHI-DAD

or continuing care facility; other

\section{Type of OAC user}

\section{Incident: patients who were not dispensed an $\mathrm{OAC}$ in the year prior to cohort entry \\ Prevalent \\ Non-switchers: patients who were dispensed the same OAC in the year prior to cohort entry \\ Switchers: patients who were dispensed a different OAC in the year prior to cohort entry} ODB

\section{Comorbidities}

Components of $\mathrm{CHA}_{2} \mathrm{DS}_{2}$-VASc (not including those mentioned above) - looking at the presence of these medical conditions in the 3 years prior to cohort entry

$\begin{array}{ll}\text { Congestive heart failure } & \text { CHF } \\ \text { Hypertension } & \text { HYPER } \\ \text { Diabetes mellitus } & \text { ODD } \\ \begin{array}{l}\text { Prior stroke/transient ischaemic } \\ \text { stroke }\end{array} & \text { CIHI-DAD } \\ \text { Peripheral vascular disease } & \end{array}$

Continued
Table 4 Continued

Variable Data source

Components of HAS-BLED (not including those mentioned above) - looking at the presence of these medical conditions in the 3 years prior to cohort entry

\begin{tabular}{|c|c|}
\hline Abnormal renal/liver function & CIHI-DAD, OHIP \\
\hline Prior bleeding & CIHI-DAD \\
\hline Drugs/alcohol concomitantly & CIHI-DAD, ODB \\
\hline Charlson comorbidity score & CIHI-DAD \\
\hline \multicolumn{2}{|l|}{ Other comorbidities } \\
\hline Dementia & DEMENTIA \\
\hline Delirium & CIHI-DAD, OMHRS \\
\hline $\begin{array}{l}\text { Diagnosis of obesity in the } 3 \text { years } \\
\text { prior to cohort entry }\end{array}$ & \multirow[t]{2}{*}{ CIHI-DAD, OHIP } \\
\hline $\begin{array}{l}\text { Diagnosis of underweight in the } 3 \\
\text { years prior to cohort entry }\end{array}$ & \\
\hline $\begin{array}{l}\text { Antiphospholipid syndrome in the } \\
3 \text { years prior to cohort entry }\end{array}$ & CIHI-DAD \\
\hline Active cancer & OCR, OHIP \\
\hline Thromboembolic event & $\begin{array}{l}\text { CIHI-DAD, CIHI- } \\
\text { NACRS }\end{array}$ \\
\hline $\begin{array}{l}\text { Substance abuse } \\
\text { Alcoholic abuse }\end{array}$ & $\begin{array}{l}\text { CIHI-DAD, OMHRS, } \\
\text { OHIP }\end{array}$ \\
\hline $\begin{array}{l}\text { Number of hospitalisations in the } \\
\text { past year }\end{array}$ & CIHI-DAD \\
\hline $\begin{array}{l}\text { Recent anticoagulant use (120 } \\
\text { days) }\end{array}$ & ODB \\
\hline \multicolumn{2}{|l|}{ Indications } \\
\hline Atrial fibrillation & $\begin{array}{l}\text { CIHI-DAD, CIHI- } \\
\text { NACRS, OHIP }\end{array}$ \\
\hline Joint replacement & CIHI-DAD \\
\hline Major surgery & CIHI-DAD \\
\hline $\begin{array}{l}\text { Deep vein thrombosis or pulmonary } \\
\text { embolism }\end{array}$ & $\begin{array}{l}\text { CIHI-DAD, CIHI- } \\
\text { NACRS }\end{array}$ \\
\hline Mechanical heart valve & CIHI-DAD \\
\hline
\end{tabular}

Potential drug interactions - dispensed in the past 120 days prior to cohort entry, unless otherwise specified Non-steroidal anti-inflammatory ODB drugs*

Selective serotonin reuptake inhibitors

Amiodarone

Aspirin*

Antiplatelets

Antibiotics, dispensed in the past

30 days prior to cohort entry

Number of drugs dispensed that

potentially interact with OACs

Continuity of care - healthcare contact within $\mathbf{7}$ days of discharge from index hospitalisation 
Table 4 Continued

\begin{tabular}{ll}
\hline Variable & Data source \\
\hline $\begin{array}{l}\text { Follow-up with primary care } \\
\text { physician, nurse practitioner, medical }\end{array}$ & OHIP, HCD \\
specialist or home care services &
\end{tabular}

Follow-up with familiar hospital OHIP
physician

Follow-up with familiar community OHIP

physician

${ }^{*}$ Over-the-counter use of drug is not captured.

CAPE, Client Agency Program Enrollment Database; CCRS,

Ontario Continuing Care Reporting System; $\mathrm{CHA}_{2} \mathrm{DS}_{2}$-VASc, congestive heart failure, hypertension, age $\geq 75$ years, diabetes, previous stroke, vascular disease, age 65-74 years, sex category; CHF, Ontario Congestive Heart Failure Database; CIHI-DAD, Canadian Institute for Health Information-Discharge Abstract Database; CIHI-NACRS, Canadian Institute for Health InformationNational Ambulatory Care Reporting System; DEMENTIA, Ontario Dementia Database; HAS-BLED, hypertension, abnormal renal/ liver function, stroke, bleeding history or predisposition, labile international normalised ratio (excluded), elderly (>65 years), drugs/alcohol concomitantly; HCD, Ontario Home Care Database; HYPER, Ontario Hypertension Dataset; IPDB, ICES Physician Database; OCR, Ontario Cancer Registry; ODB, Ontario Drug Benefit Programme Database; ODD, Ontario Diabetes Database; OHIP, Ontario Health Insurance Plan Claims History Database; OMHRS, Ontario Mental Health Reporting System Database; RAICA, Resident Assessment Instrument-Contact Assessment; RAIHC, Resident Assessment Instrument-Home Care; RPDB, Ontario Health Insurance Plan Registered Persons Database.

type of discharge will be captured. We will also capture specialty of the physician responsible for index OAC prescription and OAC dispensed at index prescription date. The cohort will be categorised into three categories of OAC users including incident, prevalent non-switchers and prevalent switchers.

Existing comorbidities may be associated with outcomes $^{55-57}$; therefore, comorbidities including dementia and diabetes will be captured. ${ }^{33} 34$ In addition, patients with a history of substance or alcohol abuse in the past 3 years prior to cohort entry will be identified. ${ }^{58}$ A diagnosis of obesity, underweight, antiphospholipid syndrome, and delirium will also be captured. Patients with active cancer, defined as individuals who received a cancer diagnosis, cancer-related surgery, chemotherapy or radiation in the past 180 days, will be identified. Hospitalisation or ED visits in the 3 years prior to cohort entry for thromboembolic or haemorrhagic events will also be recorded.

Several indices, including the Deyo-Charlson Comorbidity Index, a general comorbidity measure developed to predict mortality, will also be calculated to describe the cohort. ${ }^{59}$ Validated clinical scores used to guide anticoagulation of patients including the congestive heart failure, hypertension, age $\geq 75$ years, diabetes, previous stroke, vascular disease, age 65-74 years, sex category $\left(\mathrm{CHA}_{2} \mathrm{DS}_{2}-\mathrm{VASc}\right)$ risk stratification scheme for predicting thromboembolism in patients with $\mathrm{AF}$ will be calculated. ${ }^{60}$ Additionally, the hypertension, abnormal renal/liver function, stroke, bleeding history or predisposition, labile international normalised ratio, elderly (>65 years), drugs/alcohol concomitantly (HAS-BLED) score, which was developed to support clinical decision making regarding anticoagulant therapy in $\mathrm{AF}$ patients by predicting bleeding risk in these patients, will be calculated. ${ }^{61}$ Since data on labile international normalised ratio are not available, this will not be calculated as part of the score.

Indications that result in the prescription of OACs will also be recorded to control for confounding by indication, including presence of $\mathrm{AF}$ in the 10 years prior to cohort entry, joint replacement (hip or knee arthroplasty) in the 35 days prior to cohort entry, major surgery lasting 120 min or longer (excluding same day surgery) during index hospitalisation, presence of a mechanical heart valve and deep vein thrombosis or pulmonary embolism during index hospitalisation. ${ }^{62-64}$ These indications will be inferred from corresponding diagnosis and procedure information, as indications for prescriptions are not recorded in Ontario prescription drug claims.

We will be adjusting for the presence of drug therapies hypothesised to influence the risk of our outcome through potential interactions with OACs by including use of prescription non-steroidal anti-inflammatory drugs, selective serotonin reuptake inhibitors, amiodarone, prescription aspirin and antiplatelets use in the 120 days prior to cohort entry and antibiotic use in the 30 days prior to cohort entry. ${ }^{64-66}$ Recent pre-hospital anticoagulant use was also captured.

Continuity of care will be operationalised to measure whether follow-up was performed by a primary care physician, nurse practitioner, medical specialist or home care services within 7 days of discharge. This measure will help gauge how well outpatient care is coordinated with hospital care as this is an important aspect of care coordination that may help reduce hospital readmissions. ${ }^{6768} \mathrm{In}$ addition, we will capture whether patients had a follow-up visit within 1 week post-discharge with any physician with whom they had had at least two visits in the 12 months preceding the index hospitalisation (community physician) or at least one visit during the hospital stay (hospital physician).${ }^{10}$ Research studies have reported that seeing a physician who is familiar with the patient's health posthospitalisation may have a beneficial impact on follow-up rates and reduce risk of death or re-admissions. ${ }^{69}$

\section{Quality checks, missing data and extreme values}

Data are unlikely to be missing at random. ${ }^{41}{ }^{52} 70$ For categorical variables, an additional 'missing' category will be included. If $\geq 10 \%$ of observations are missing, multiple imputations are planned.

\section{Bias}

Bias in pharmacoepidemiology studies results from multiple sources of confounding. ${ }^{6717} 72$ DOAC users tend to be younger with fewer comorbidities than warfarin 
users. ${ }^{73}$ To control for confounding, we will include variables such as age, sex, presence of specific comorbidities, concomitant medications, remote residence, neighbourhood income quintile and physician specialty among other independent variables in the model as potential risk factors. Furthermore, the inclusion criteria for study participants may exclude prevalent OAC users who have an existing supply of OACs. This biases the study cohort to include more patients who start OAC therapy posthospitalisation. However, the current participant inclusion criteria allow us to study the impact of the index hospitalisation on outcomes for OAC users.

Given that continuity of care risk factors are hypothesised to be important in the early period after hospital discharge for OAC-related adverse events, the outcome observation period will begin after 7 days post-discharge to avoid survivor-treatment bias. ${ }^{74}$ We will report the number of patients excluded due to the occurrence of an event during the blanking period.

\section{Sample size}

For Cox regression, a fitted model is likely to be reliable and stable when the number of participants with the outcome (ie, either first hospitalisation or ED visit during follow-up for a haemorrhage or arterial or venous thromboembolic event, or death) is 20 times the number of covariates. ${ }^{75}$ We anticipate that up to 30 covariates will be included in the Cox regression model; therefore, a minimum of 600 patients with at least one of the outcomes that form the composite will be required to devise the models in this cohort. This is feasible as a similar study reported haemorrhage and thromboembolic event rates of about 26 and 34 per 100 person-years in the first 30-day post-discharge, respectively, in a cohort of 123140 patients. $^{8}$ In addition, the long accrual period will also help ensure a sufficient sample size.

\section{Statistical plan}

All data will be examined using descriptive statistics. Categorical variables will be summarised using frequency and percentage. Continuous variables will be summarised using mean and SD or median and IQR, when results are skewed. Person-time of follow-up will also be captured.

A summary of all planned analysis is provided in table 5. Given that the primary outcome is a time-toevent outcome, Cox proportional hazards model will be used to determine the association between the composite outcome and all risk factors including patient demographic, index hospitalisation descriptors, comorbidity, drug indications, potential drug interactions and continuity of care variables within 1 month of hospital discharge.

\section{Model construction}

Model derivation and validation will be based on a splitsample method. ${ }^{76}$ Two-thirds of the study participants will be randomly assigned to a model derivation cohort, and one-third will be reserved as an independent validation cohort. ${ }^{77}$ Both cohorts will be compared with respect to clinical and continuity of care variables.

The model will be developed based on data from the derivation cohort alone. For the primary outcome, because predictors that are highly correlated with others contribute little independent information, pruning candidate predictors will be required. ${ }^{78}$ The effect of multicollinearity between predictors would inflate the variance of the coefficient estimates and makes the estimates very sensitive to minor changes in the model. To avoid this, multicollinearity among the covariates will be explored using tolerance statistics and variance inflation factor. Tolerance statistic of below 0.1 and a variance inflation factor of above 10 will indicate multicollinearity. Of the highly correlated independent variables, one will be removed from the model based on clinical judgement.

Subsequently, univariate Cox regression models will be used to select variables for entry into the multivariable regression model. If the $p$ value of a variable is less than or equal to 0.20 , that variable will be included in the model building stage of the final multivariate regression model.

To investigate whether significant covariates can modify the effect of other predictors in the Cox proportional hazards model, two-way interactions between clinically significant predictors will be tested. Significant interactions with a $\mathrm{p}$ value of $\leq 0.05$ will be retained and added into the prediction model.

Finally, since this is an exploratory analysis, a backward stepwise approach will be employed for selection of risk factors for inclusion in the final multivariate Cox model. ${ }^{79}$ Least significant independent variables including confounding variables will be removed until all $p$ values are below 0.2 . The continuity of care variable, hypothesised to significantly impact the survival of the patient, will be retained in the model. Risk factors with the effects from the Cox proportional hazard's model expressed as the HR, corresponding 95\% CI and the associated $\mathrm{p}$ value will be reported. The proportionality assumption will be assessed using Schonfeld residuals and interaction of risk factors with time. ${ }^{80}$ If proportionality assumption is not met, results will be stratified if appropriate. All violations of the proportionality assumption will be reported.

\section{Sensitivity analysis}

There is much debate on effect of OACs on acute myocardial infarction. Meta-analyses of RCTs have concluded that the use of dabigatran is associated with an increased risk of acute myocardial infarction. ${ }^{81} 82$ Given the evidence on risk for acute myocardial infarction in dabigatran users, a sensitivity analysis with this event in the definition of the composite outcome will be performed using the aforementioned methods.

Moreover, a competing risk analysis is planned where all-cause mortality will be treated as a competing risk for haemorrhagic and thromboembolic events. A 
Table 5 Statistical plan summary

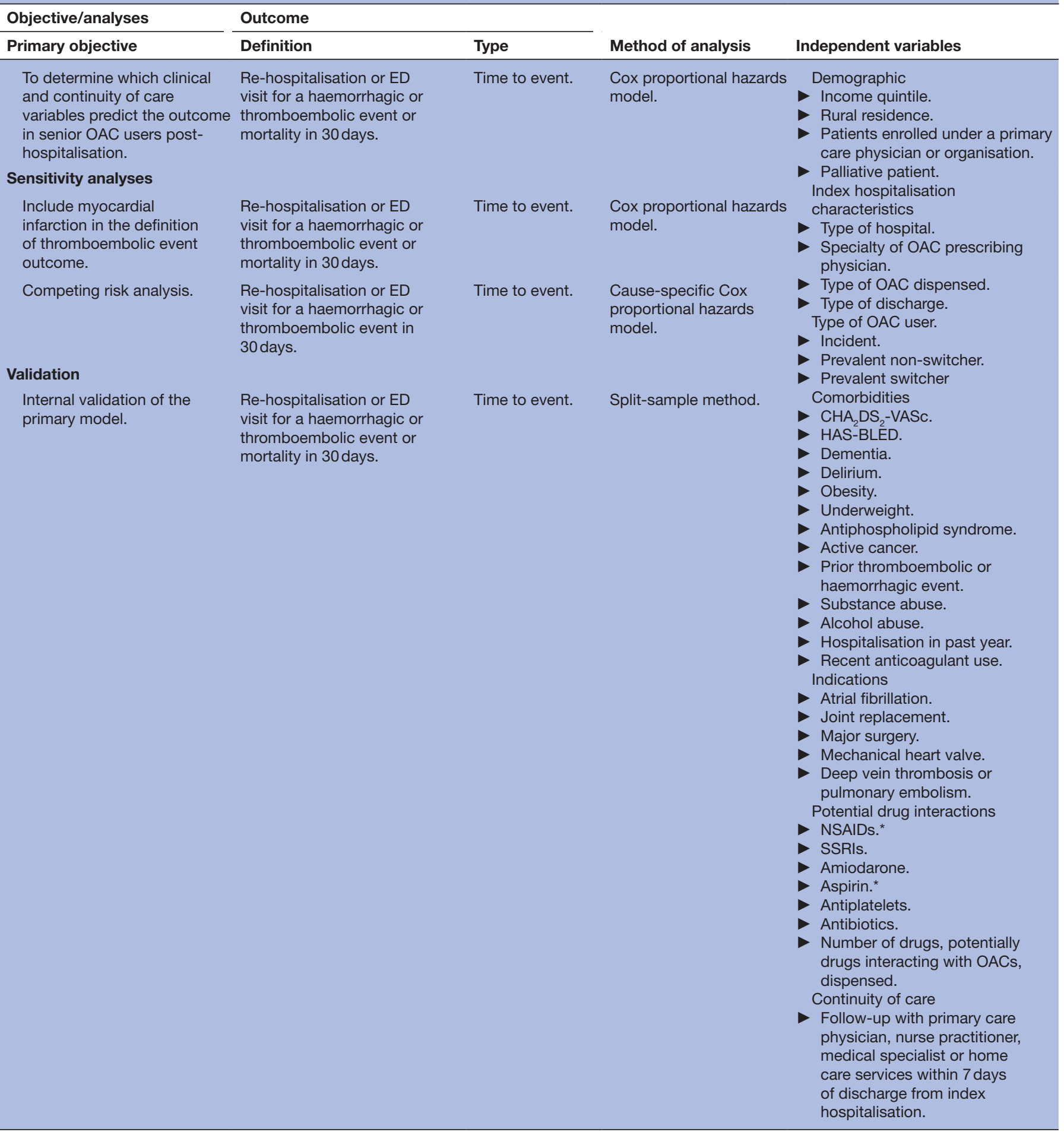

*Over-the-counter use of drug is not captured.

$\mathrm{CHA}_{2} \mathrm{DS}_{2}$-VASc, congestive heart failure, hypertension, age $\geq 75$ years, diabetes, previous stroke, vascular disease, age 65-74 years, sex category; ED, emergency department; HAS-BLED, hypertension, abnormal renal/liver function, stroke, bleeding history or predisposition, labile international normalised ratio (excluded), elderly (>65 years), drugs/alcohol concomitantly; NSAIDs, non-steroidal anti-inflammatory drugs; OAC, oral anticoagulant; SSRIs, selective serotonin reuptake inhibitors.

cause-specific Cox proportional hazards model will be constructed ${ }^{83}$ Predictors and their coefficients in the cause-specific hazard models will be compared with those in the full Cox model.
Model validation

Once the final model is developed, it will be assessed in the separate validation cohort of patients. The predictive accuracy of the model will be assessed using tests 
for discrimination and calibration. ${ }^{80}$ We will evaluate the model calibration by conducting the Gronnesby and Borgan Test, which uses martingale residuals to compare the count of events to the semi-parametric estimates from the Cox proportional hazards model on a cumulative hazards scale. ${ }^{80}$ Discrimination will be evaluated using Harell's C-index representing the area under the receiver operating characteristic curve with larger values indicating better discrimination. ${ }^{80}$

Data management and analysis will be performed using SAS V.9.4 (SAS Institute Inc., Cary, NC, USA).

\section{Patient and public involvement}

The publicly funded research programme that includes this study has several patient co-investigators and advisors. Input from 19 patients participating in focus groups on barriers and facilitators for optimal OAC management provided suggestions for predictors. Patients did not contribute to the actual writing or editing of this document.

\section{ETHICS AND DISSEMINATION}

All study data reside and are analysed at ICES (www.ices. on.ca). ICES is a prescribed entity under Section 45 of Ontario's Personal Health Information Protection Act. Section 45 authorises ICES to collect personal health information, without consent, for the purpose of analysis or compiling statistical information with respect to the management of, evaluation or monitoring of, the allocation of resources to or planning for all or part of the health system. Projects conducted under section 45, by definition, do not require review by a Research Ethics Board. This project was conducted under section 45 and was approved by ICES' Privacy and Legal Office.

The results of this study will be published in a peerreviewed journal and presented at national and international conferences. They will also help determine intervention targets to improve OAC management in upcoming randomised trials.

\section{Author affiliations \\ ${ }^{1}$ Department of Health Research Methods, Evidence, and Impact, McMaster University, Hamilton, Ontario, Canada \\ ${ }^{2}$ Department of Medicine, Division of Clinical Pharmacology \& Toxicology, McMaster University, Hamilton, Ontario, Canada \\ ${ }^{3}$ ICES, Toronto, Ontario, Canada \\ ${ }^{4}$ Institute of Health Policy, Management and Evaluation, University of Toronto, Toronto, Ontario, Canada \\ ${ }^{5}$ Department of Medicine, Division of Hematology and Thromboembolism, McMaster University, Hamilton, Ontario, Canada \\ ${ }^{6}$ Thrombosis and Atherosclerosis Research Institute, Hamilton, Ontario, Canada \\ ${ }^{7}$ Biostatistics Unit, Saint Joseph's Healthcare Hamilton, Hamilton, Ontario, Canada}

\section{Collaborators None Declared.}

Contributors $\mathrm{AH}$ obtained the funding and developed the study idea. $\mathrm{HB}$ and $\mathrm{AH}$ designed the study. $\mathrm{HB}$ obtained data permissions and research ethics approvals. LT, MP and GF contributed to the study design, methodology and analysis plan. AH and JD provided clinical guidance, AH developed the outcome data sets and MP provided expertise in large administrative health databases housed at ICES in designing the study. HB drafted the initial manuscript, and all authors critiqued the protocol manuscript. All authors approve the attached manuscript for publication and take accountability for all aspects of the work.

Funding This work is supported by a grant from the Canadian Institutes for Health Research - grant \# 365834 and the Hamilton Academic Health Sciences Organization - grant \# HAH-16-06 awarded to AH. This study was also supported by ICES, which is funded by an annual grant from the Ontario Ministry of Health and Long-Term Care (MOHLTC). Parts of this material are based on information compiled and provided by the MOHLTC, Cancer Care Ontario and the Canadian Institute for Health Information. We would like to thank IMS Brogan Inc for use of their Drug Information Database.

Disclaimer The conclusions, opinions and statements expressed herein are those of the authors and do not necessarily reflect those of the funding or data sources; no endorsement is intended or should be inferred.

Competing interests None declared.

Patient consent for publication Not required.

Provenance and peer review Not commissioned; externally peer reviewed.

Open access This is an open access article distributed in accordance with the Creative Commons Attribution Non Commercial (CC BY-NC 4.0) license, which permits others to distribute, remix, adapt, build upon this work non-commercially, and license their derivative works on different terms, provided the original work is properly cited, appropriate credit is given, any changes made indicated, and the use is non-commercial. See: http://creativecommons.org/licenses/by-nc/4.0/.

ORCID iD

Anne Holbrook http://orcid.org/0000-0002-3371-4187

\section{REFERENCES}

1 GYH L, Banerjee A, Boriani G, et al. Antithrombotic therapy for atrial fibrillation. Chest 2018;154:1121-201.

2 Kearon C, Akl EA, Ornelas J, et al. Antithrombotic therapy for VTe disease. Chest 2016;149:315-52.

3 Steffel J, Verhamme P, Potpara TS, et al. The 2018 European heart rhythm association practical guide on the use of non-vitamin $\mathrm{K}$ antagonist oral anticoagulants in patients with atrial fibrillation. Eur Heart J 2018;39:1330-93.

4 Witt DM, Nieuwlaat R, Clark NP, et al. American Society of hematology 2018 guidelines for management of venous thromboembolism: optimal management of anticoagulation therapy. Blood Adv 2018;2:3257-91.

5 Institute for Safe Medication Practices. ISMP list of high-alert medications in acute care settings, 2014. Available: http://www.ismp. org/Tools/institutionalhighAlert.asp [Accessed 25 May 2019].

6 Shehab N, Lovegrove MC, Geller Al, et al. Us emergency department visits for outpatient adverse drug events, 2013-2014. JAMA 2016;316:2115-25

7 Canadian Institute for Health Information. Adverse drug ReactionRelated hospitalizations among seniors, 2006 to 2011. Ottawa, 2013. Available: https://secure.cihi.ca/free_products/Hospitalizations

8 Holbrook A, Paterson M, Martins D, et al. Patient transitions and oral anticoagulant safety: a population-based cohort. Can J Cardiol 2018;34:S27-8.

9 Chen LM, Ayanian JZ. Care continuity and care coordination: what counts? JAMA Intern Med 2014;174:749.

10 (ClHI) $\mathrm{Cl}$ for HI. Physician follow-up after hospital discharge: progress in meeting best practices. Available: https://secure.cihi.ca/ estore/productFamily.htm?locale=en\&pf=PFC2840 [Accessed 17 May 2019].

11 World Health Organization. Continuity and coordination of care: a practical brief to support implemntation of the who framework on integrated people-centred health services. Geneva, 2018.

12 Misky GJ, Wald HL, Coleman EA. Post-hospitalization transitions: examining the effects of timing of primary care provider follow-up. $J$ Hosp Med 2010;5:392-7.

13 Lin CY, Barnato AE, Degenholtz HB. Physician follow-up visits after acute care hospitalization for elderly Medicare beneficiaries discharged to noninstitutional settings. J Am Geriatr Soc 2011;59:1947-54.

14 Shen E, Koyama SY, Huynh DN, et al. Association of a dedicated Post-Hospital discharge follow-up visit and 30-day readmission risk in a Medicare advantage population. JAMA Intern Med 2017:177:132.

15 Hernandez AF, Greiner MA, Fonarow GC, et al. Relationship between early physician follow-up and 30-day readmission among Medicare beneficiaries hospitalized for heart failure. JAMA 2010;303:1716-22. 
16 Sharma G, Kuo Y-F, Freeman JL, et al. Outpatient follow-up visit and 30-day emergency department visit and readmission in patients hospitalized for chronic obstructive pulmonary disease. Arch Intern Med 2010:170:1664-70.

17 Delgado Guay MO, Guay MOD, Tanzi S, et al. Characteristics and outcomes of advanced cancer patients who miss outpatient supportive care consult appointments. Support Care Cancer 2014;22:2869-74.

18 Tung Y-C, Chang G-M, Chang H-Y, et al. Relationship between early physician follow-up and 30-day readmission after acute myocardial infarction and heart failure. PLoS One 2017;12:e0170061.

19 Howlett JG, McKelvie RS, Costigan J, et al. The 2010 Canadian cardiovascular Society guidelines for the diagnosis and management of heart failure update: heart failure in ethnic minority populations, heart failure and pregnancy, disease management, and quality improvement/assurance programs. Can J Cardiol 2010;26:185-202.

20 Albert NM, Barnason S, Deswal A, et al. Transitions of care in heart failure. Circulation 2015;8:384-409.

21 Halasyamani L, Kripalani S, Coleman E, et al. Transition of care for hospitalized elderly patients--development of a discharge checklist for hospitalists. J Hosp Med 2006;1:354-60

22 American College of Cardiology. Hospital to home. Available: https:// cvquality.acc.org/initiatives/hospital-to-home [Accessed 25 May 2019]

23 Health Quality Ontario. Health Quality Ontario. Quality Monitor: 2010 Report on Ontario's Health System. Toronto, 2010. Available: http:// www.hqontario.ca/portals/0/Documents/pr/ qmonitor-full-report2012-en.pdf

24 Health PEI. Chronic obstructive pulmonary disease clinical pathway. Cbarlottetown, 2011. Available: http://www.gov.pe.ca/photos/ original/hpei_clinicalpa.pdf

25 Donaldson LJ, Kelley ET, Dhingra-Kumar N, et al. Medication without harm: who's third global patient safety challenge. Lancet 2017;389:1680-1.

26 Aitken M, Gorokhovich L. Advancing the responsible use of medicines: applying levers for change. SSRN Journal 2012

27 Institute of Medicine. Preventing medication errors. Washington: The National Academic Press, 2007

28 Feigenbaum P, Neuwirth E, Trowbridge L, et al. Factors contributing to all-cause 30-day readmissions. Med Care 2012;50:599-605.

29 Suissa S, Garbe E. Primer: administrative health databases in observational studies of drug effects--advantages and disadvantages. Nat Clin Pract Rheumatol 2007;3:725-32.

30 Hashimoto RE, Brodt ED, Skelly AC, et al. Administrative database studies: goldmine or goose Chase? Evid Based Spine Care J 2014;5:74-6.

31 Statistics Canada. Population estimates on July 1st, by age and sex, 2018. Available: https://www150.statcan.gc.ca/t1/tbl1/en/tv.action? pid=1710000501 [Accessed 25 May 2019].

32 Schultz SE, Rothwell DM, Chen Z, et al. Identifying cases of congestive heart failure from administrative data: a validation study using primary care patient records. Chronic Dis Inj Can 2013;33:160-6.

33 Jaakkimainen RL, Bronskill SE, Tierney MC, et al. Identification of Physician-Diagnosed Alzheimer's Disease and Related Dementias in Population-Based Administrative Data: A Validation Study Using Family Physicians' Electronic Medical Records. JAD 2016;54:337-49.

34 Hux JE, Ivis F, Flintoft V, et al. Diabetes in Ontario: determination of prevalence and incidence using a validated administrative data algorithm. Diabetes Care 2002;25:512-6.

35 Tu K, Chen Z, Lipscombe LL, et al. Prevalence and incidence of hypertension from 1995 to 2005: a population-based study. CMAJ 2008;178:1429-35

36 Tu K, Campbell NR, Chen Z-L, et al. Accuracy of administrative databases in identifying patients with hypertension. Open Med 2007;1:e18-26.

37 Wells G, Coyle D, Cameron C, et al. Safety, effectiveness, and costeffectiveness of new oral anticoagulants compared with warfarin in preventing stroke and other cardiovascular events in patients with atrial fibrillation. Canadian Agency for Drugs and Technologies in Health2012.

38 van der Linden CMJ, Jansen PAF, van Geerenstein EV, der LCMJvan, van GEV, et al. Reasons for discontinuation of medication during hospitalization and documentation thereof: a descriptive study of 400 geriatric and internal medicine patients. Arch Intern Med 2010;170:1085-7.

39 Viktil KK, Blix HS, Eek AK, et al. How are drug regimen changes during hospitalisation handled after discharge: a cohort study. BMJ Open 2012;2:e001461.

40 Little D, Chai-Adisaksopha C, Hillis C, et al. Resumption of anticoagulant therapy after anticoagulant-related gastrointestinal bleeding: a systematic review and meta-analysis. Thromb Res 2019;175:102-9

41 Levy AR, O'Brien BJ, Sellors C, et al. Coding accuracy of administrative drug claims in the Ontario drug benefit database. Can J Clin Pharmacol 2003;10:67-71.

42 Connolly SJ, Ezekowitz MD, Yusuf S, et al. Dabigatran versus warfarin in patients with atrial fibrillation. $N$ Engl J Med 2009;361:1139-51.

43 Patel MR, Mahaffey KW, Garg J, et al. Rivaroxaban versus warfarin in nonvalvular atrial fibrillation. N Engl J Med 2011;365:883-91.

44 Granger CB, Alexander JH, McMurray JJV, et al. Apixaban versus warfarin in patients with atrial fibrillation. $N$ Engl J Med 2011;365:981-92.

45 Varadhan R, Weiss CO, Segal JB, et al. Evaluating health outcomes in the presence of competing risks. Med Care 2010;48:S96-105.

46 Andersen PK, Geskus RB, de Witte T, et al. Competing risks in epidemiology: possibilities and pitfalls. Int J Epidemiol 2012;41:861-70.

47 Tamariz L, Harkins T, Nair V. A systematic review of validated methods for identifying venous thromboembolism using administrative and claims data. Pharmacoepidemiol Drug Saf 2012;21 Suppl 1:154-62.

48 Sanfilippo KM, Wang T-F, Gage BF, et al. Improving accuracy of international classification of diseases codes for venous thromboembolism in administrative data. Thromb Res 2015;135:616-20.

49 Arnason T, Wells PS, van Walraven C, et al. Accuracy of coding for possible warfarin complications in hospital discharge Abstracts. Thromb Res 2006;118:253-62.

50 White RH, Garcia M, Sadeghi B, et al. Evaluation of the predictive value of ICD-9-CM coded administrative data for venous thromboembolism in the United States. Thromb Res 2010;126:61-7.

51 Birman-Deych E, Waterman AD, Yan Y, et al. Accuracy of ICD-9-CM codes for identifying cardiovascular and stroke risk factors. Med Care 2005;43:480-5.

52 Juurlink D, Preyra C, Croxford R, et al. Canadian Institute for health information discharge Abstract database: a validation study. Toronto, 2006. Available: https://www.ices.on.ca/Publications/Atlases-andReports/2006/Canadian-Institute-for-Health-Information [Accessed 28 May 2019].

53 Quan H, Li B, Saunders LD, et al. Assessing validity of ICD-9-CM and ICD-10 administrative data in recording clinical conditions in a unique dually coded database. Health Serv Res 2008;43:1424-41.

54 Tanuseputro P, Budhwani S, Bai YQ, et al. Palliative care delivery across health sectors: a population-level observational study. Palliat Med 2017;31:247-57.

55 Steinberg BA, Greiner MA, Hammill BG, et al. Contraindications to anticoagulation therapy and eligibility for novel anticoagulants in older patients with atrial fibrillation. Cardiovasc Ther 2015;33:177-83.

56 Decousus H, Tapson VF, Bergmann J-F, et al. Factors at admission associated with bleeding risk in medical patients. Chest 2011;139:69-79.

57 Schünemann $\mathrm{HJ}$, Cushman $\mathrm{M}$, Burnett $\mathrm{AE}$, et al. American Society of hematology 2018 guidelines for management of venous thromboembolism: prophylaxis for hospitalized and nonhospitalized medical patients. Blood Adv 2018;2:3198-225.

58 MHASEF Research Team. Mental health and addictions system performance in Ontario: a baseline Scorecard. Toronto, 2018.

59 Quan H, Li B, Couris CM, et al. Updating and validating the Charlson comorbidity index and score for risk adjustment in hospital discharge Abstracts using data from 6 countries. Am J Epidemiol 2011;173:676-82.

60 Pisters R, Lane DA, Nieuwlaat R, et al. A novel user-friendly score (HAS-BLED) to assess 1-year risk of major bleeding in patients with atrial fibrillation: the Euro heart survey. Chest 2010;138:1093-100.

61 Olesen JB, Lip GYH, Hansen ML, et al. Validation of risk stratification schemes for predicting stroke and thromboembolism in patients with atrial fibrillation: nationwide cohort study. BMJ 2011;342:d124.

62 Douketis JD, Spyropoulos AC, Spencer FA, et al. Perioperative management of antithrombotic therapy. Chest 2012;141:e326S-50.

63 Adam SS, McDuffie JR, Ortel TL, et al. Comparative effectiveness of warfarin and new oral anticoagulants for the management of atrial fibrillation and venous thromboembolism: a systematic review. Ann Intern Med 2012;157:796.

64 Hinojar R, Jiménez-Natcher JJ, Fernández-Golfín C, et al. New oral anticoagulants: a practical guide for physicians. Eur Heart $J$ Cardiovasc Pharmacother 2015;1:134-45.

65 Vranckx P, Valgimigli M, Heidbuchel $\mathrm{H}$. The significance of drugdrug and Drug-Food interactions of oral anticoagulation. Arrhythm Electrophysiol Rev 2018;7:55-61. 
66 Sayani S, lqbal O, Hoppensteadt D, et al. Drug interactions of newer oral anticoagulants dabigatran, rivaroxaban, and apixaban with routinely used Nonanticoagulant/Antiplatelet drugs. Blood 2014;124:4267.

67 Liu A, Abrahamowicz M, Siemiatycki J. Conditions for confounding of interactions. Pharmacoepidemiol Drug Saf 2016;25:287-96.

68 Health Quality Ontario. Quality in primary care: setting a foundation for monitoring and reporting in Ontario. Toronto, 2015.

69 Lapointe-Shaw L, Mamdani M, Luo J, et al. Effectiveness of a financial incentive to physicians for timely follow-up after hospital discharge: a population-based time series analysis. CMAJ 2017;189:E1224-9.

70 van Walraven C, Mamdani M, Fang J, et al. Continuity of care and patient outcomes after hospital discharge. J Gen Intern Med 2004;19:624-31.

71 Williams JI, Young W. A Summary of Studies on the Quality of Health Care Administrative Databases in Canada. In: Goel V, Williams JI, Anderson GM, et al, eds. Patterns of health care in Ontario, the ICES practice atlas. 2nd edn. Ottawa: Canadian Medical Association, 1996: 339-45.

72 Kyriacou DN, Lewis RJ. Confounding by indication in clinical research. JAMA 2016;316:1818-9.

73 Csizmadi I, Collet J-P, Boivin J-F. Bias and confounding in pharmacoepidemiology. in: pharmacoepidemiology. Chichester, UK: John Wiley \& Sons, Ltd, 2006: 791-809.
74 Austin PC, Mamdani MM, van Walraven C, et al. Quantifying the impact of survivor treatment bias in observational studies. J Eval Clin Pract 2006;12:601-12.

75 Ogundimu EO, Altman DG, Collins GS. Adequate sample size for developing prediction models is not simply related to events per variable. J Clin Epidemiol 2016;76:175-82.

76 Faraway JJ. Does data splitting improve prediction? Stat Comput 2016;26:49-60.

77 Picard RR, Berk KN. Data splitting. Am Stat 1990;44:140.

78 Royston P, Moons KGM, Altman DG, et al. Prognosis and prognostic research: developing a prognostic model. BMJ 2009;338:b604.

79 Derksen S, Keselman HJ, Backward KHJ. Backward, forward and stepwise automated subset selection algorithms: frequency of obtaining authentic and noise variables. Br J Math Stat Psychol 1992;45:265-82.

80 Harrell FE, Lee KL, Mark DB. Multivariable prognostic models: issues in developing models, evaluating assumptions and adequacy, and measuring and reducing errors. Stat Med 1996;15:361-87.

81 Uchino K, Hernandez A V. Dabigatran association with higher risk of acute coronary events. Arch Intern Med 2012;172:397.

82 Clemens A, Fraessdorf M, Friedman J. Cardiovascular outcomes during treatment with dabigatran: comprehensive analysis of individual subject data by treatment. Vasc Health Risk Manag 2013;9:599-615.

83 Austin PC, Lee DS, Fine JP. Introduction to the analysis of survival data in the presence of competing risks. Circulation 2016;133:601-9. 